\title{
In situ stress estimation using acoustic televiewer data
}

\author{
SD Goodfellow KORE Geosystems, Canada
}

B Simser Glencore, Canada

C Drielsma DGI Geoscience, Canada

V Gerrie KORE Geosystems, Canada

\begin{abstract}
A good understanding of stress in deep, high-stress mine environments is of critical importance to geomechanical modelling, mine design and ground control. Stress is traditionally a challenging and expensive measurement, and the available methods produce sparse data that are subject to high levels of uncertainty. In this paper, the authors present a method for obtaining principal stress orientations and constraints on relative magnitude from acoustic televiewer (ATV) breakout data. The method uses breakout orientation data from multiple deviated boreholes (from horizontal to vertical) across a volume of interest. This method assumes the volume is homogenous and linear elastic to calculate the theoretical location of breakout along each borehole. Next, a global optimisation algorithm steps through all possible stress states until it finds the global minimum, which minimises the angular residual between the observation and theory. ATV data is continuous, and thus the stress state resulting from this method is supported by hundreds of observations. Lastly, the authors present the results from a case study at a deep mine in Sudbury, where breakout data from 10 boreholes (horizontal and sub-vertical) were used to calculate the principal stress orientations. These results were discussed and compared with world stress map results.
\end{abstract}

Keywords: rock mechanics, stress orientation, seismicity, numerical modelling, geomechanics, instrumentation, modelling

\section{Introduction}

A good understanding of local stress conditions is of critical importance for mine design and mine management. During the mine design phase of a mining operation, the mine plan is engineered. This includes the geometry of the final, completed mine, excavation sequence, and ground support design. Mine design is conducted using numerical modelling and analytical techniques. The primary inputs for these models are principal stress orientations and magnitudes, geology, mechanical rock properties and rock failure criteria. Once a mine is operational, the safety of employees working underground is of the utmost importance, and for this, a good understanding of stress is of critical importance.

Stress is traditionally a challenging quantity to measure because it can be highly variable across a region of interest and the available methods can be time-consuming, expensive, have high rates of failure, can produce sparse measurements, and can have high levels of variability. The most common methods for measuring stress are overcoring, microseismic interpretation, mini-hydraulic fracturing, and acoustic emission Kaiser effect method.

The authors propose a stress estimation method that uses borehole breakouts measured with an ATV to invert for principal stress orientations and provide constraints on relative magnitude. This method can produce rapid results, using data that typically already exists, and includes a robust uncertainty analysis to allow engineers to understand the confidence of the resulting stress model. 


\section{Methodology}

This technique takes ATV borehole breakout picks from multiple deviated boreholes and finds the best matching stress state. This is possible given the well documented and modelled relationship between breakout orientation and stress (Mastin 1988). The following is a description of the applied methodology.

\subsection{Acoustic televiewer data}

An ATV probe obtains a high-resolution, oriented acoustic image of the borehole wall, using a rotating sensor that transmits ultrasound pulses towards the borehole. These pulses reflect off the borehole wall and back to the receiver, where the amplitude of the reflected signal and the travel time are recorded. If there are fractures or breakout present on the borehole wall, the time taken for the pulse to travel there and back will be greater, as reflected in the travel time log, and the relative amplitude of the pulse will be attenuated, as reflected in the amplitude log.

Figure 1 presents an example of an ATV imaged breakout section. The raw ATV images of travel time and ultrasonic amplitude are manually picked for breakouts. Breakout sections are described by their length, high side angle, tilt, width, and distance downhole.
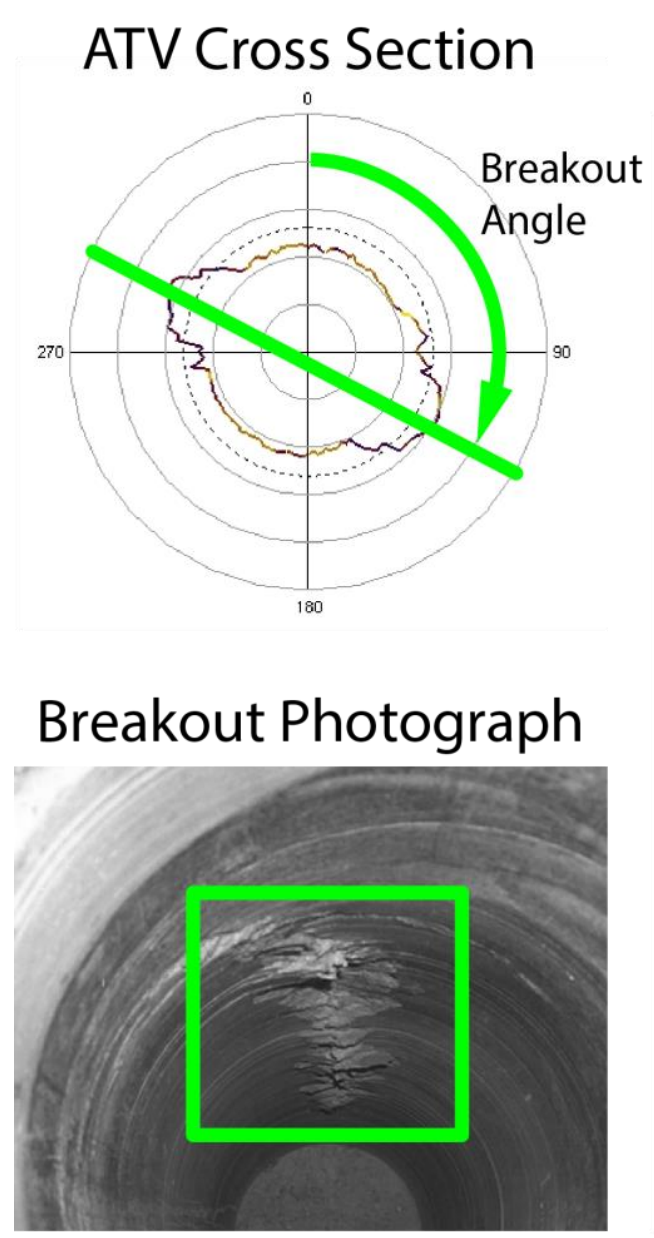

\section{High Side Angle}
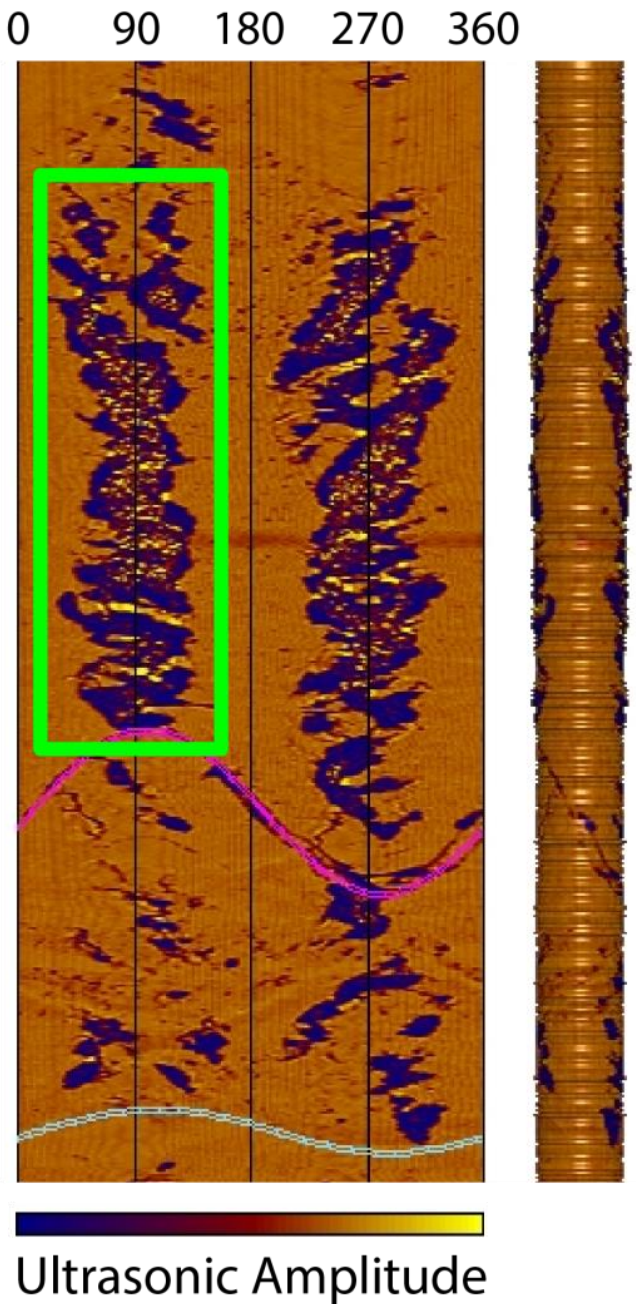

Figure 1 ATV image of borehole breakouts 


\subsection{Borehole coordinate system}

In the case of a perfectly linear borehole, its geometry is described by two parameters: borehole azimuth $(\delta)$ and tilt $(\Omega)$, as shown in Figure 2. In practice, boreholes are not perfectly linear, and therefore, to measure their geometry, deviation surveys are conducted at regular intervals downhole. The deviation survey measures borehole azimuth and tilt as a function of distance downhole.

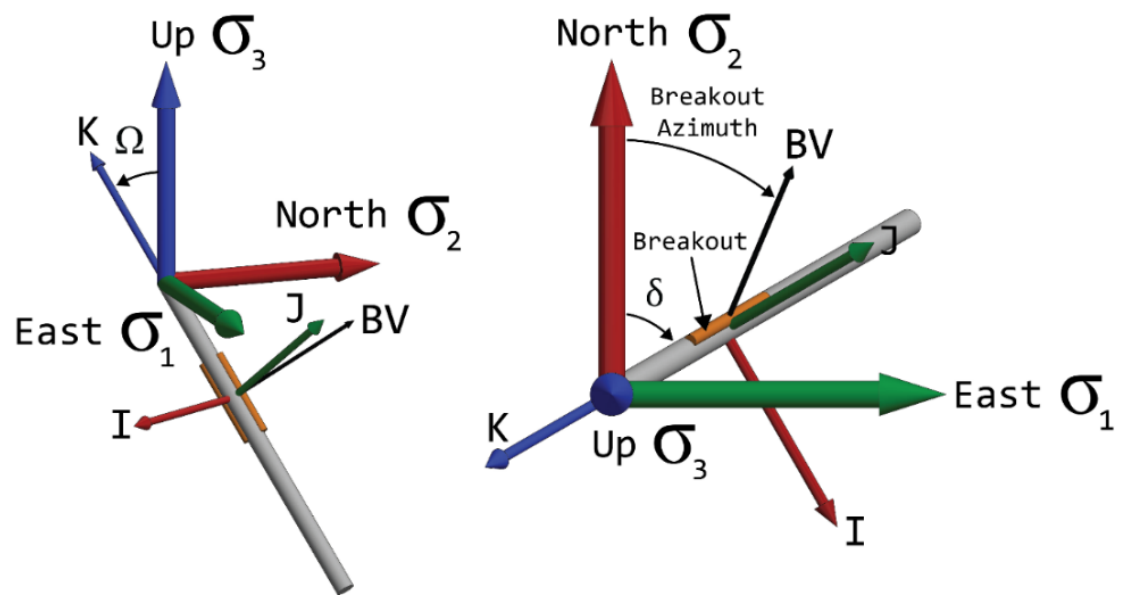

Figure 2 Borehole coordinate system

\subsection{Borehole breakout coordinate systems}

In this study, the authors use three coordinate systems when working with borehole breakout data:

1. High side coordinate system.

2. IJK coordinate system.

3. Breakout azimuth coordinate system (NEU).

An example of borehole breakout data plotted in each coordinate system is presented in Figure 3 . The high side breakout angle is measured clockwise from the high side (up-side) of the borehole. The IJK coordinate system is another borehole coordinate system, similar to the high side coordinate system, where the J-axis points to the borehole high side, the K-axis points up the borehole axis, and the J-axis is orthogonal to I and $\mathrm{J}$ following the right-hand rule. In the IJK coordinate system, zero degrees is at the I-axis, and the angle increases in the counter clockwise direction. The breakout azimuth coordinate system is measured clockwise from north and indicates the direction of breakout on a deviated borehole projected on the northeast (horizontal) plane. See Figure 2 for a graphical depiction of breakout azimuth.
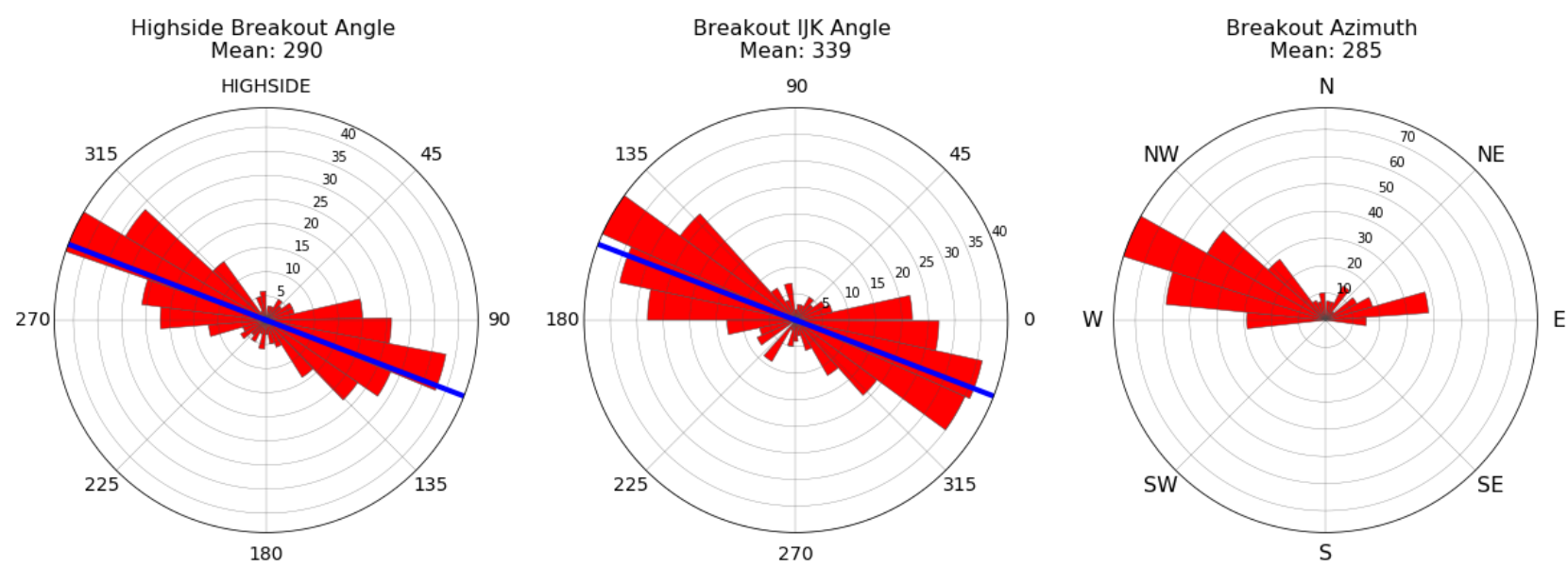

Figure 3 Breakout coordinate systems 
Figure 4 displays the geometry for a vertical and deviated borehole and the associated polar plots. The polar plots present the trend of the borehole as a coloured circle, and the orientation of breakout as a straight line. The orientation of the straight line is a graphical representation of the breakout azimuth. This plot is helpful for showing borehole trend and breakout trend in a single plot.
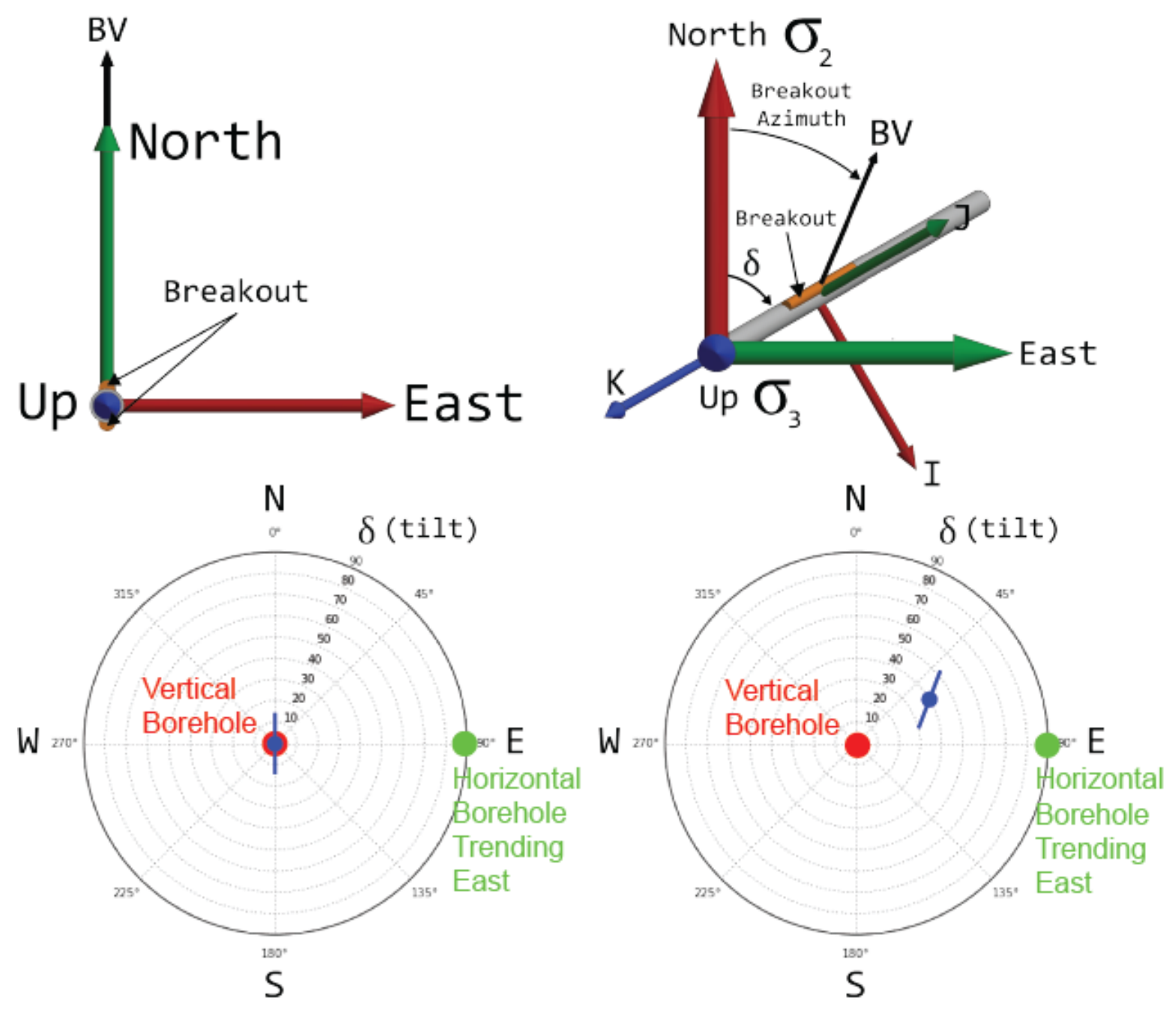

Figure 4 Example of breakout orientation (breakout azimuth) plotted on a polar diagram. The breakout vector (BV) points in the direction of breakout on the borehole wall and is perpendicular to the borehole axis at the point where breakout is observed

\subsection{Stress inversion}

The inversion is set up as a forward modelling optimisation problem. In this framework, optimisation is done to find the stress state that produces theoretical breakout orientations that best matches the observed breakout orientations. The forward modelling calculates the theoretical orientation of breakout given some stress state. The theoretical orientation of breakout is calculated as the point on the borehole wall where the tangential stress is maximum. For this calculation, it is assumed that the rock volume is homogeneous, isotropic and linear elastic.

The stress state is parameterised by four parameters following the formulation of Zajac and Stock (1997). Three are Euler angles and the fourth is the stress ratio, which is calculated using Equation 1.

$$
\phi=\frac{\sigma_{2}-\sigma_{3}}{\sigma_{1}-\sigma_{3}}
$$


Given a stress state, defined by three Euler angles and the stress ratio, and a borehole orientation, defined by azimuth and tilt, the position of breakout on the borehole wall can be calculated. Breakout will occur at the point on the borehole wall where the compressive stress is maximum.

The objective of the optimisation process is to find the stress state that produces theoretical breakout angles that best match the observed breakout angles. In this step, we use a brute force forward modelling technique to search all possible stress states for the global optimum. At each step, a misfit value is calculated, which is a quantitative measure of the quality of the fit.

\subsection{Uncertainty analysis}

An uncertainty analysis is conducted to assess the stability of the resulting stress model, given that sometimes this data can exhibit a high degree of noise. The authors use a Monte Carlo method to assess uncertainty given the robustness of the method. The method works by rerunning the stress inversion procedure multiple times (simulations) where some random angular noise has been added to each of the measured breakout orientations. Three separate uncertainty analyses are run with increasing levels of noise (larger standard deviations). One hundred simulations are run for each analysis to produce a large enough number of data points to make the results statistically significant. For the three analyses, noise is randomly sampled from a normal distribution with standard deviations equal to (i) $5^{\circ}$, (ii) $15^{\circ}$, and (iii) the observed distributions from the raw data. This analysis helps assess how well each stress model parameter is constrained.

\section{Application}

In this section, we will present the results from an analysis conducted in a deep mine ( $>2 \mathrm{~km})$. ATV data were collected on 10 deviated boreholes located in a common region of the mine, and with a common depth interval. The boreholes range from vertical to horizontal.

\subsection{Borehole breakout and survey data}

Figure 5 presents the breakout data for each borehole. The figures include polar plots of breakout orientations (high side, IJK, and breakout azimuth coordinate systems), borehole azimuth and tilt as a function of distance downhole, breakout orientation and length as a function of distance downhole, and polar plots of borehole trend and breakout azimuth. For each borehole, the mean and standard deviation breakout angle was computed (Table 1). Statistical calculations were done using a diametrically bimodal circular distribution.

Table 1 Borehole list

\begin{tabular}{lllll}
\hline Borehole ID & Mean azimuth $\left(^{\circ}\right)$ & Mean tilt $\left(^{\circ}\right)$ & Max. depth $(\mathbf{m})$ & Breakout count \\
\hline 1 & 354.18 & 34.15 & 390.51 & 177 \\
2 & 271.35 & 80.24 & 475.53 & 108 \\
3 & 302.15 & 79.37 & 454.71 & 327 \\
4 & 354.66 & 9.81 & 778.17 & 294 \\
5 & 301.52 & 27.97 & 974.02 & 253 \\
6 & 20.30 & 11.70 & 722.19 & 256 \\
7 & 24.58 & 17.81 & 654.29 & 361 \\
8 & 278.52 & 78.65 & 278.31 & 68 \\
9 & 344.12 & 7.41 & 740.9 & 376 \\
10 & 302.07 & 27.99 & 877.77 & 355 \\
\hline
\end{tabular}



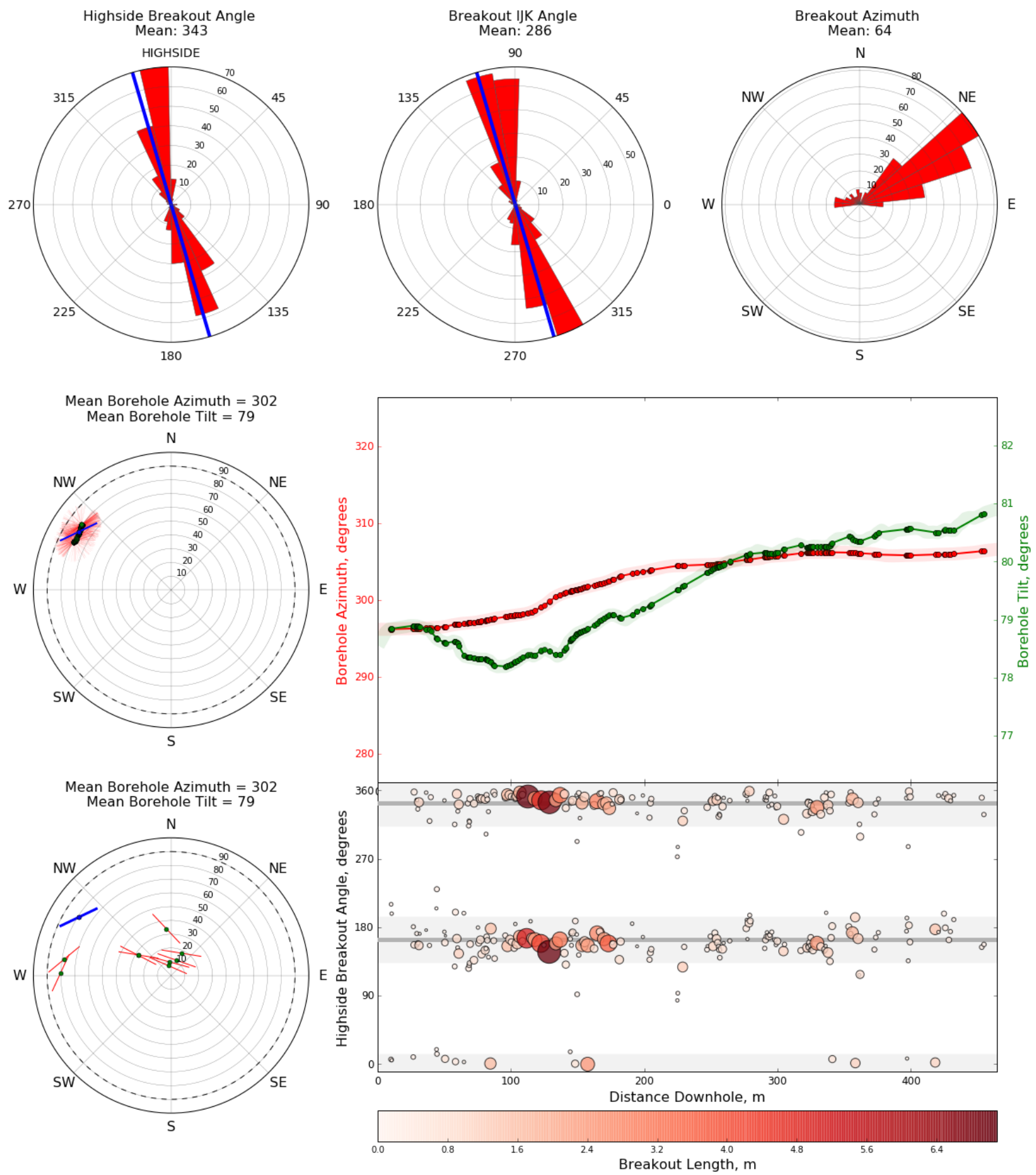

Figure 5 Borehole breakout and survey data for borehole 3

In some cases, the first 100-200 m of breakout information was not used to calculate the mean and standard deviation breakout angle for each borehole. These regions are selected by hand in the case where large deviations from the mean trends are observed and likely a result of stress rotations induced by the proximity to the underground opening. Once a borehole is sufficiently far from the opening, it is assumed that far field region stress conditions are controlling breakout orientations. 


\subsection{Stress inversion}

A stress inversion analysis was conducted using the average breakout orientations for each of the 10 deviated boreholes. This meant the stress model was fit to 10 observation points. The global optimisation algorithm was run five times with randomly selected initial guesses. This was to ensure that the global minimum was located.

The results from the stress inversion are presented in Figure 6 and indicate $\sigma_{1}$ striking $20^{\circ}$ from north and $\sigma_{3}$ pointing sub-vertical, suggesting a thrust faulting stress regime. Figure 6 presents the principal stress orientations in polar and 3D plots, and a plot that allows a visual assessment of the goodness of fit. The red dashes indicate the observed direction of breakout (breakout azimuth) on the 10 boreholes, and the black dashes indicate the modelled direction of breakout for a range of possible borehole orientations (azimuth $0-360^{\circ}$, tilt $\left.0-90^{\circ}\right)$. These results suggest a good fit between observation and model for both sub-vertical and sub-horizontal boreholes. Also presented in Figure 6 is a plot showing stress ratio versus objective function value. For this plot, the principal stress orientations are fixed to the global minimum values, and the stress ratio is increased from zero to one. This helps assess how well constrained the stress ratio is. The global minimum stress ratio value is 0.907 and appears to be well constrained.

Global Minimum

Delta $=-30.795$

Omega $=196.375$

Psi $=319.932$

Stress Ratio $=0.907$

Function Value $=0.187$
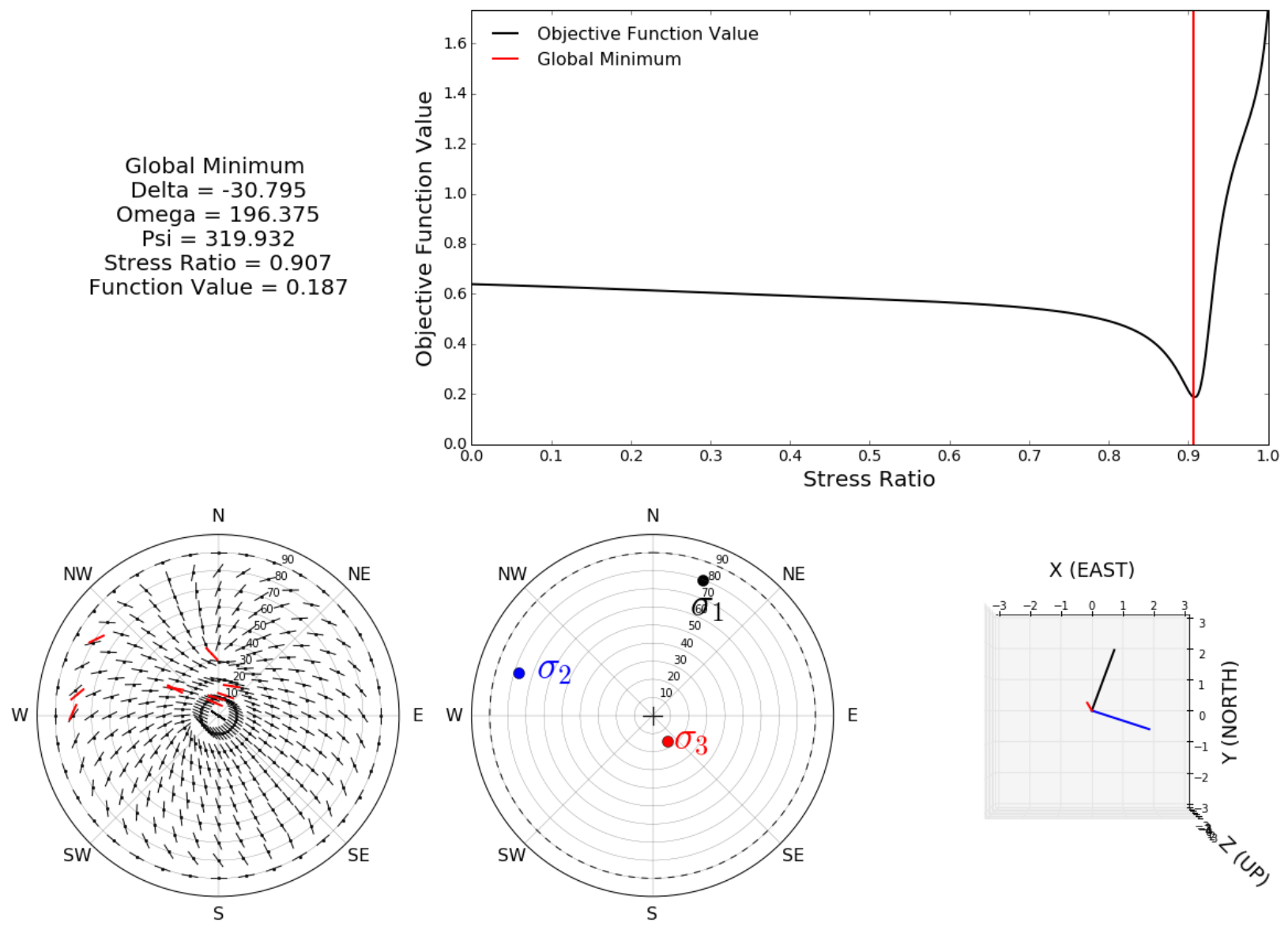

Figure 6 Stress inversion results

Figure 7 displays another view that allows for the quality of fit to be assessed. In this plot, the raw IJK breakout orientations (grey) are plotted along with the mean observed IJK breakout orientations (red) and the modelled IJK breakout orientations (black). 
Hole ID: 1

Angular Difference: 2 deg

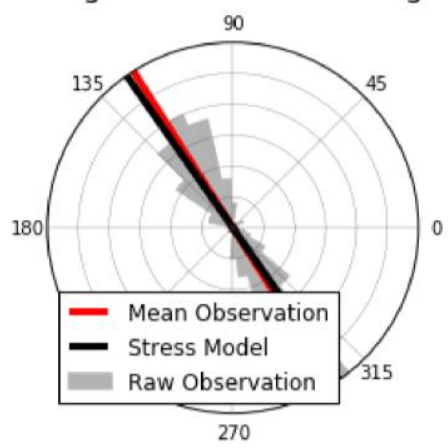

Hole ID: 4

Angular Difference: 4 deg

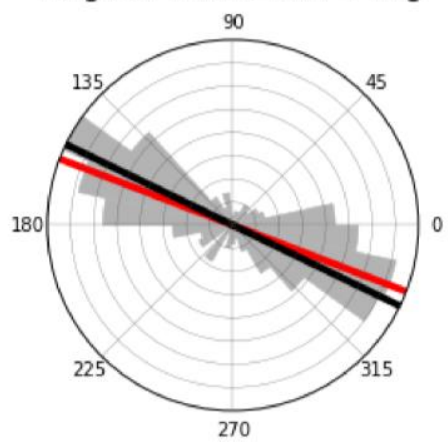

Hole ID: 7

Angular Difference: 4 deg

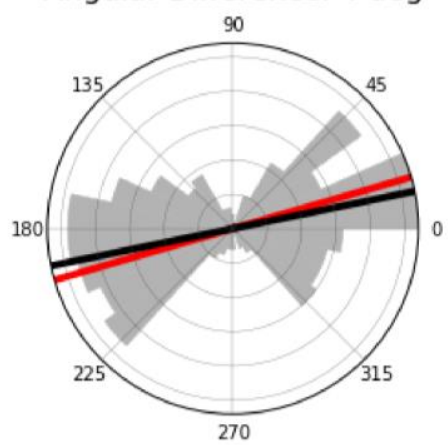

Hole ID: 10

Angular Difference: 0 deg

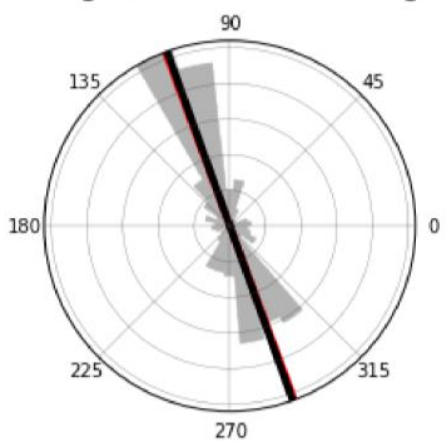

Hole ID: 2

Angular Difference: 9 deg

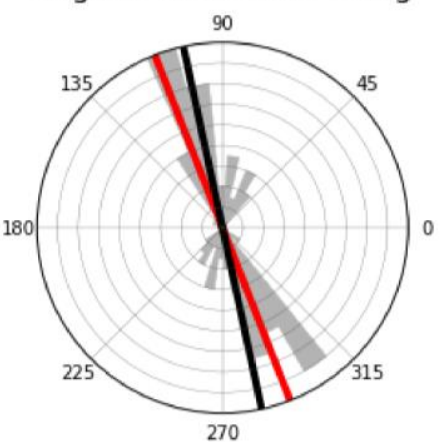

Hole ID: 5

Angular Difference: 15 deg

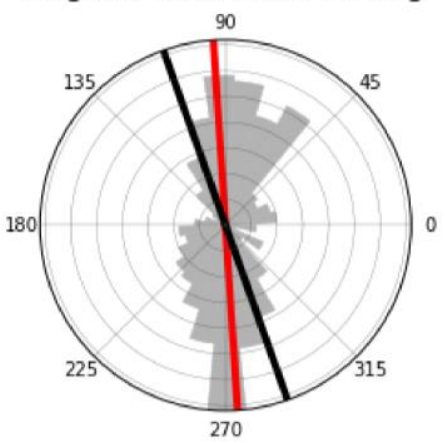

Hole ID: 8

Angular Difference: 0 deg

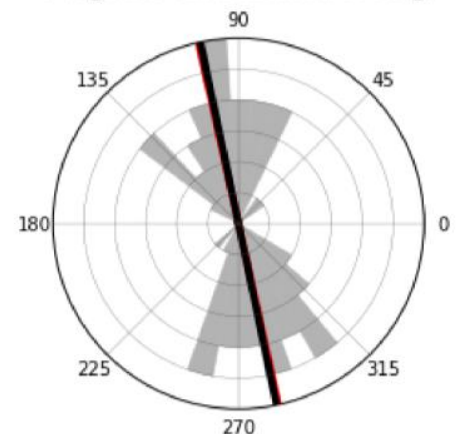

Hole ID: 3

Angular Difference: $6 \mathrm{deg}$

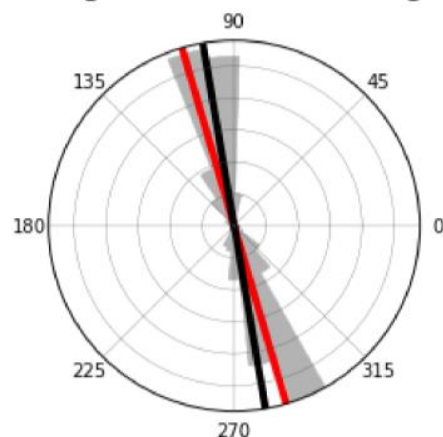

Hole ID: 6

Angular Difference: 0 deg

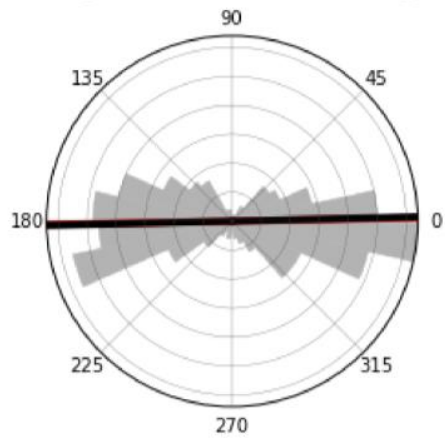

Hole ID: 9

Angular Difference: $1 \mathrm{deg}$

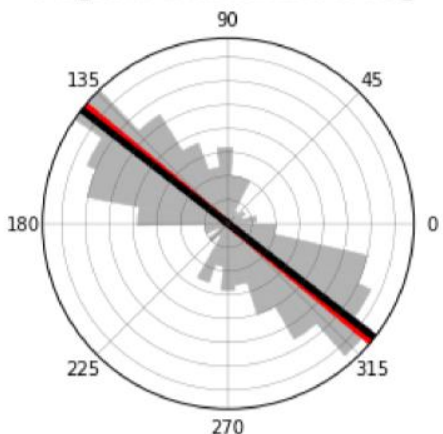

Figure 7 Breakout orientations: observed versus modelled 


\subsection{Uncertainty analysis}

An uncertainty analysis was conducted to assess the stability of the resulting stress model given that high degrees of noise were observed for some boreholes. Figures 8,9 , and 10 present the uncertainty analysis results. In Figure 8, we added random noise sampled from a normal distribution with $5^{\circ}$ standard deviation. For this noise level, the model appears to be very well constrained, with principal stress orientation not varying significantly. When the noise level was increased to $15^{\circ}$, some inversions produced outlying points, but generally, the model remained well constrained.
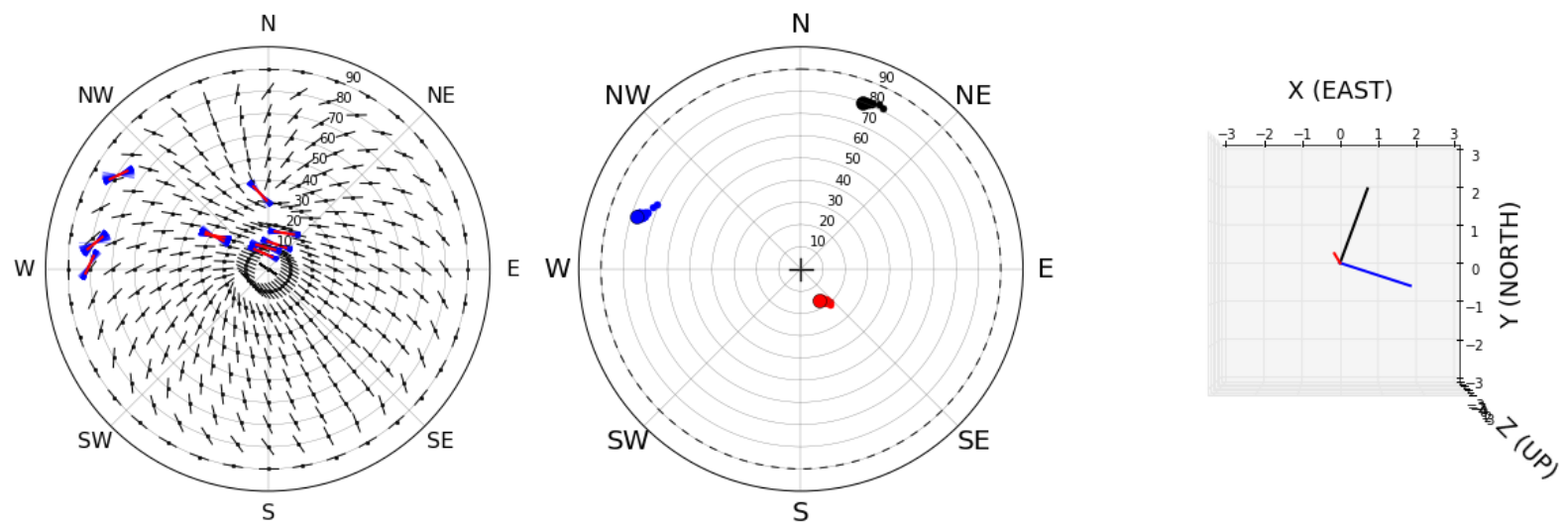

Figure 8 Monte Carlo uncertainty analysis results sampling from angular noise with $5^{\circ}$ standard deviation
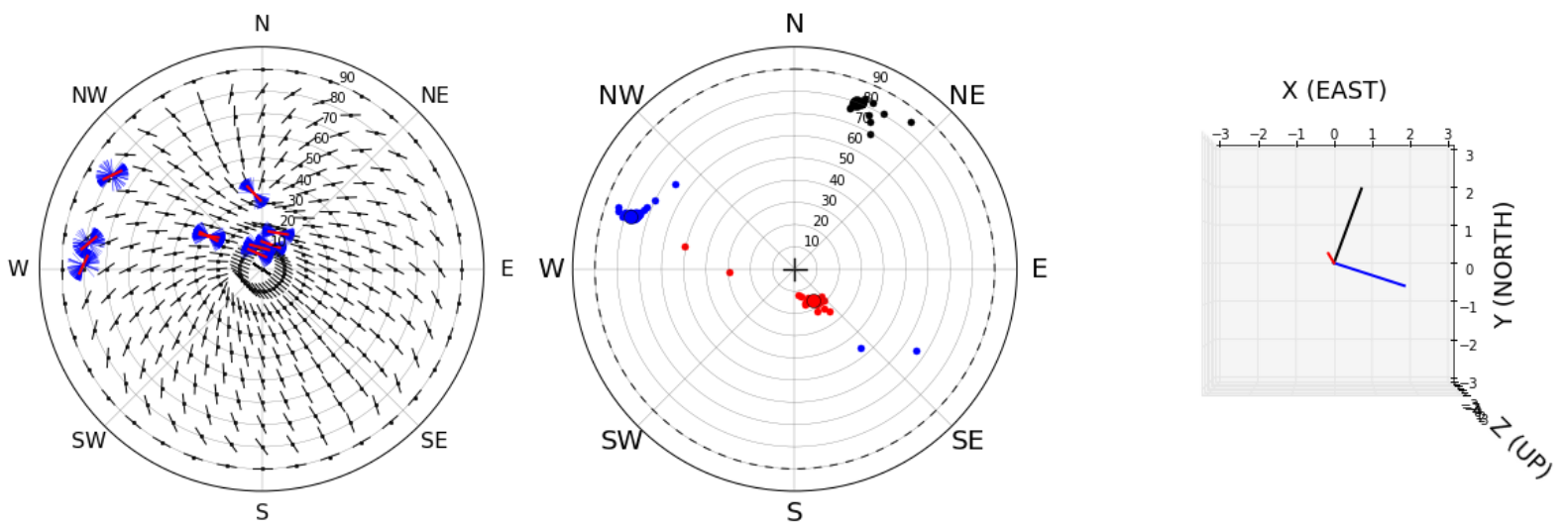

Figure 9 Monte Carlo uncertainty analysis results sampling from angular noise with $15^{\circ}$ standard deviation
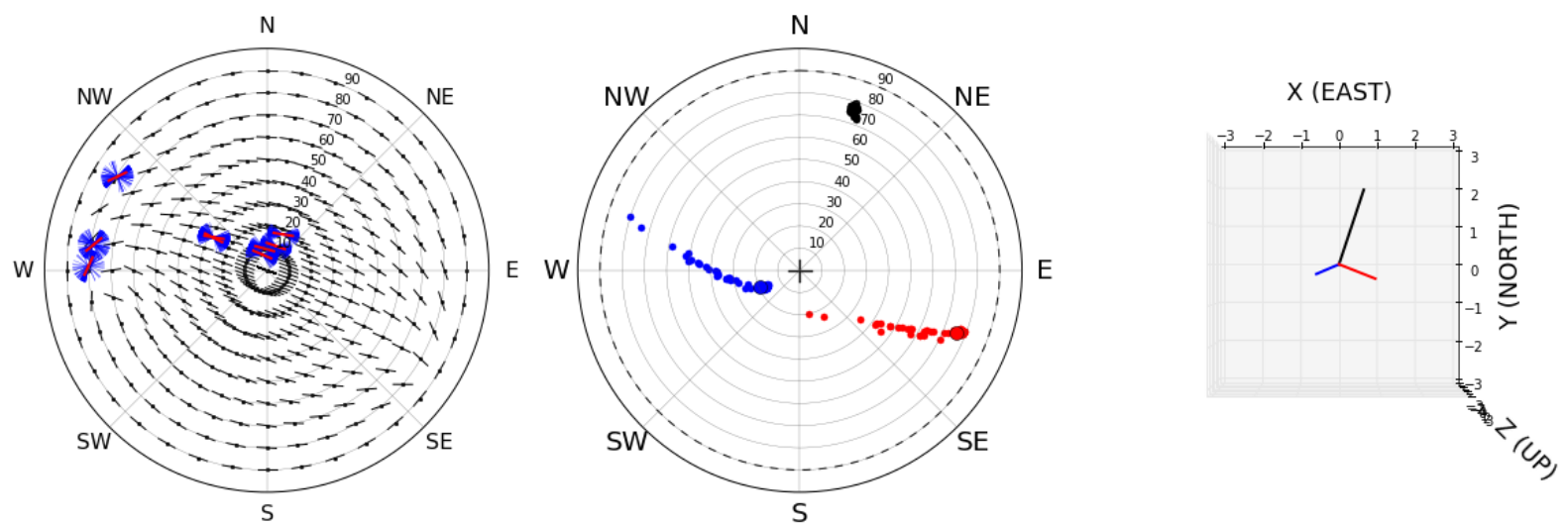

Figure 10 Monte Carlo uncertainty analysis results sampling from angular noise with $15^{\circ}$ standard deviation where one borehole (borehole 1 ) has been removed 
To show an example of when a model is not well constrained, Figure 10 shows the uncertainty analysis results where borehole 1 has been removed. It can now be seen that the orientation of $\sigma_{1}$ remains well constrained, but $\sigma_{2}$ and $\sigma_{3}$ are free to rotate around $\sigma_{1}$.

\section{$4 \quad$ Conclusions}

In this paper, we have described a method to obtain principal stress orientations and constraints on relative magnitude from ATV breakout data. We presented the results from the application of this method to breakout data from 10 boreholes in a deep $(>2 \mathrm{~km})$ mine.

The main disadvantages of this method are that it:

- Requires the presence of breakouts, and therefore can only be used in high-stress or weak rock environments.

- Is not formatted to handle strength anisotropy.

- Requires boreholes with varied orientations.

- Does not provide an estimate of absolute stress magnitudes.

The benefits of this method over traditional methods are the following:

- The measurements are in situ and can be obtained in virgin or active areas.

- ATV data has often already been collected given that it has other applications, such as fracture and fault imaging, and true orientation.

- The stress inversion uses continuous, high-resolution data from a range of borehole orientations. This makes improvements over the sparse data problem with traditional measurements.

- The results are available shortly after the collection of the data.

- Uncertainty analyses are included to help understand the significance of the results.

- Once the mean stress trend is quantified, continuous data can be analysed per local deviations from the mean. This could be used to identify potentially hazardous regions of the mine where significant stress rotations are observed.

\section{Acknowledgement}

The authors acknowledge Roxanne LeBlanc and Pamela Patraskovic of DGI Geoscience Inc. for processing the raw ATV data.

\section{References}

Mastin, B 1988, 'Effect of borehole deviation on breakout orientations', Journal of Geophysical Research, vol. 93, no. B8, pp. 9187-9195.

Zajac, B \& Stock, J 1997, 'Using borehole breakouts to constrain the complete stress tensor: Results from the Sijan Deep Drilling Project and offshore Santa Maria Basin, California', Journal of Geophysical Research, vol. 102, no. B5, pp. 10083-10100. 